\title{
Efeito do Extrato de Urucum na Pigmentação da Gema dos Ovos
}

\author{
José Humberto Vilar da Silva ${ }^{1}$, Luiz Fernando Teixeira Albino², Mauro José de Souza Godói ${ }^{3}$
}

RESUMO - O trabalho foi realizado para avaliar níveis de adição do extrato de urucum (EU) a uma ração em que o sorgo foi utilizado como principal fonte de energia. Um total de 280 poedeiras no segundo ciclo de produção, 140 Lohmann Selected Leghorn (LSL) e 140 Isa Brown (IB), foi alojado em densidade de duas aves/gaiola e alimentado ad libitum com sete rações. Os tratamentos consistiram de uma ração controle positiva com milho, como principal fonte de energia, e uma ração basal contendo sorgo, como principal fonte de energia, suplementada com seis níveis de EU em 0,$0 ; 0,10 ; 0,15 ; 0,30 ; 0,45 ;$ e $0,60 \%$. O delineamento foi inteiramente ao acaso em esquema fatorial 7 x 2 (tratamento e linhagem), com cinco repetições de quatro aves. A adição de EU à ração à base de sorgo melhorou a pigmentação da gema dos ovos linearmente. A linhagem IB apresentou melhor pigmentação da gema dos ovos que a linhagem LSL. Os resultados permitiram concluir que a adição de $0,1 \%$ de EU à ração com sorgo promoveu similar pigmentação da gema do ovo que a ração à base de milho.

Palavras-chave: corante natural, pigmentação da gema, urucum

\section{Effect of Anatto Extract Oil on the Egg Yolk Colour}

\begin{abstract}
The experiment was carried out to evaluate the increasing levels of anatto extract (AE) oil in sorghum-based diets as the main energy source. A total of 280 laying hens in the second production cycle, 140 Lohmann Selected Leghorn (LSL) and 140 Isa Brown (IB), was allotted to a density two birds/pen and full fed seven diets. The treatments consisted of a positive control corn based diet, as principal energy source, and a basal sorghum diet, as principal energy source, supplemented with $0.0,0.10,0.15,0.30,0.45$, and $0.60 \%$ of AE. A completely randomized design in a $7 \times 2$ factorial arrangement (treatment and line), with five replicates of four birds, was used. The egg yolk colour was linearly improved by addition of $\mathrm{AE}$ to the sorghum-based diets. The brown-egg layers presented better egg yolk colour than the white-egg layers. The addition of $0.1 \%$ AE to the sorghum-based diets produced similar egg yolk colour as the corn based diets.
\end{abstract}

Key Words: anatto oil extract, egg yolk colour, natural colorant

\section{Introdução}

As rações formuladas para poedeiras comerciais contêm o milho amarelo como principal fonte de energia e de pigmentos naturais, como xantofilas, que contribuem para produção de uma gema de coloração alaranjada. Entretanto, em caso de disponibilidade de sorgo, mandioca, farelo de arroz, milheto, algaroba e adlai, em algumas regiões do país, o produtor deve substituir o milho parcial ou totalmente, em função da necessidade de redução dos custos de produção.

Entretanto, dependendo do nível de inclusão dessas matérias-primas nas rações de postura, pode ocorrer redução severa da coloração da gema, causando a recusa dos ovos por parte dos consumidores, exigindo a adição de corantes artificiais ou naturais à ração. A opção pelos corantes naturais tem aumentado, em virtude das restrições dos consumidores e das legislações dos países que proíbem a adição de corantes sintéticos às rações animais e aos alimentos humanos.
$\mathrm{Na}$ Itália, por exemplo, com a proibição do uso de corantes artificiais nos alimentos, o pigmento bixina, extraído do urucum, tem sido adicionado às rações de poedeiras, para conferir coloração à gema do ovo e, assim, colorir as massas (DAMASCENO, 1988).

No entanto, o uso de corantes à base de urucum deve se restringir à substituição dos corantes artificiais, e não como fonte de $\beta$-caroteno ou de vitamina $A$ sintética, em virtude da falta de comprovação da atividade vitamínica do produto (VILLELA, 1942; CARVALHO e HEIN, 1989). Há informações que comprovam a ineficácia do urucum como bom pigmentante da pele de frangos de corte (WILLIAMS, 1989).

Estudos com poedeiras já demonstraram a possibilidade de o urucum, na forma de farinha, melhorar a pigmentação da gema do ovo. CAMPOS (1955) substituiu o milho (30\%) pelo adlai (Coix lacrima Jobi, Lin) e suplementou a ração com 1 e $2 \%$ de farinha de urucum. O autor sugeriu que a dose de $1 \%$ foi suficiente para produção de uma gema pigmentada,

\footnotetext{
${ }^{1}$ Departamento de Agropecuária - CFT/UFPB - Bananeiras - PB - CEP 58.220-000. E.mail: jvilar@cft.ufpb.br

2 Professor DZO/UFV - Viçosa - MG - Brasil.

3 Zootecnista - Técnico do DZO/UFV.
} 
mas a dose de $2 \%$ produziu gemas de coloração laranja forte, de maior preferência do consumidor brasileiro. Posteriormente, SANCHEZ (1965) recomendou $3 \%$ de farinha de urucum em rações em que o milho é substituído em 30 a $50 \%$ por alimentos pobres em pigmentos.

ARAYA et al. (1977) obteve cor da gema similar com a adição de $0,003 \%$ de Carophyll e dose de $1,06 \%$ da farinha da semente de urucum, quando o milho foi substituído pelo sorgo na ração de poedeiras, o que representou escore de 9 a 10 pontos, no leque colorimétrico da Roche.

O sorgo, o quinto cereal em produção no mundo, após o trigo, milho, arroz e cevada (NYACHOTI et al., 1997), custa cerca de $88 \%$ do preço do milho e vem se constituindo na mais promissora fonte de energia, em substituição ao milho, em rações de monogástricos. O valor nutricional do sorgo é $95 \%$ daquele do milho (FIALHO e BARBOSA, 1997), mas a composição protéica, o perfil e a digestibilidade verdadeira dos aminoácidos (PUPA, 1995) são muito similares aos do milho. O sorgo é mais resistente à seca, porém menos produtivo e mais pobre em pigmentos que o milho (FIALHO e BARBOSA, 1997); o seu uso em rações de poedeiras deve exigir o suprimento de corantes, porque o mercado exige ovos altamente pigmentados (LANCINI, 1994).

O extrato de urucum é um produto industrial obtido pela remoção dos pigmentos da semente de urucum (Bixa orellana L.) diluídos em solução oleosa. O extrato lipossolúvel contém vários pigmentos coloridos, sendo a bixina o principal (DAMASCENO, 1988; MASCARENHAS e STRINGHETA, 1998). Entretanto, desconhece-se qualquer informação sobre o uso deste produto como pigmentante da gema do ovo.

O objetivo deste trabalho foi avaliar o efeito de níveis crescentes do extrato de urucum, em rações em que o sorgo foi usado como principal fonte de energia, sobre o desempenho e a pigmentação da gema dos ovos de duas linhagens de postura comercial.

\section{Material e Métodos}

O experimento foi conduzido no Setor de Avicultura da Universidade Federal de Viçosa.

Foram utilizadas 280 poedeiras, submetidas à muda forçada na $85^{\mathrm{a}}$ semana de idade, sendo 140 aves leves da marca comercial Lohmann Selected Leghorn (LSL) e 140 aves semipesadas da marca comercial Isa Brown (IB).

As aves foram alojadas durante o período de produção em galpão de postura, de $60 \times 9 \mathrm{~m}$, com telas nas laterais à prova de pássaro, coberto com telhas de barro em duas águas, com dois conjuntos de quatro fileiras de gaiolas, separadas por um corredor central de $2 \mathrm{~m}$, sendo utilizadas apenas duas fileiras centrais de cada conjunto. Durante a fase de produção, o fotoperíodo utilizado foi de 16 horas por dia.

No início do período experimental, as aves tinham 90 semanas de idade, correspondendo à $5 \underline{a}$ semana após o início da postura, após a muda induzida, quando as aves atingiram taxa de postura de $50 \%$.

Foi utilizado delineamento inteiramente ao acaso em esquema fatorial $7 \times 2$ (sete tratamentos e duas linhagens), com cinco repetições e quatro aves de cada linhagem por unidade experimental.

Os tratamentos consistiram de uma ração controle positivo com milho, como principal fonte de energia, e uma ração basal contendo sorgo, como principal fonte de energia, suplementada com seis níveis de extrato oleoso de urucum (EU) em 0,$10 ; 0,15 ; 0,30$; 0,45 ; e $0,60 \%$, em substituição ao amido de milho.

As rações (Tabela 1) foram formuladas para conterem os mesmos valores de proteína, energia, fósforo disponível, cálcio, metionina, aminoácidos sulfurosos e lisina (ROSTAGNO et al., 1996), exceto o conteúdo de pigmentos.

As rações e a água foram fornecidas à vontade durante todo o período experimental. As características avaliadas foram produção de ovos, peso médio dos ovos, massa de ovos, consumo de ração, conversão alimentar e pigmentação da gema dos ovos avaliada por meio do leque colorimétrico da Roche.

Os dados obtidos foram submetidos à análise estatística, utilizando-se o programa Sistema de análises estatísticas e genéticas - SAEG (UNIVERSIDADE FEDERAL DE VIÇOSA - UFV, 1982).

\section{Resultados e Discussão}

Não houve efeito da adição do EU (Tabela 1) sobre a produção e o peso dos ovos, entretanto, nas rações com sorgo como principal fonte de energia, a adição do EU melhorou de forma linear $(\mathrm{P}<0,01)$ a pigmentação da gema (Figura 1).

Como era esperado, o grupo de aves alimentadas com a ração contendo sorgo sem o EU produziu gemas com fraca pigmentação, enquanto a adição de $0,10 \%$ de EU resultou em pigmentação similar à obtida com a ração contendo milho como principal fonte de energia.

Resultados semelhantes foram obtidos por CAMPOS 
Rev. bras. zootec.

Tabela 1 - Composição percentual das rações experimentais

Table 1 - Percentage composition of experimental diets

\begin{tabular}{|c|c|c|}
\hline \multirow[b]{2}{*}{$\begin{array}{l}\text { Ingrediente, \% } \\
\text { Ingredient }\end{array}$} & \multicolumn{2}{|c|}{ Ração } \\
\hline & $\begin{array}{l}\text { Milho } \\
\text { Corn }\end{array}$ & $\begin{array}{c}\text { Sorgo } \\
\text { Sorghum }\end{array}$ \\
\hline Milho & 63,66 & 25,45 \\
\hline $\begin{array}{l}\text { Corn } \\
\text { Sorgo }\end{array}$ & - & 41,40 \\
\hline $\begin{array}{l}\text { Sorghum } \\
\text { Farelo de soja }\end{array}$ & 22,85 & 21,45 \\
\hline $\begin{array}{l}\text { Soybean meal } \\
\text { Extrato de urucum }\end{array}$ & - & 0,00 \\
\hline $\begin{array}{l}\text { Annato extract } \\
\text { Amido de milho } \\
\text { Corn starch }\end{array}$ & - & 0,60 \\
\hline $\begin{array}{l}\text { Calcário } \\
\text { Limestone }\end{array}$ & 8,00 & 7,97 \\
\hline $\begin{array}{l}\text { Fosfato bicálcico } \\
\text { Dicalcium phosphaste }\end{array}$ & 1,31 & 1,33 \\
\hline $\begin{array}{l}\text { Óleo vegetal } \\
\text { Vegetal oil }\end{array}$ & 0,80 & 0,80 \\
\hline $\begin{array}{l}\text { Areia lavada } \\
\text { Washed sand }\end{array}$ & 2,48 & - \\
\hline $\begin{array}{l}\text { Sal comum } \\
\text { Salt }\end{array}$ & 0,42 & 0,43 \\
\hline $\begin{array}{l}\text { DL-Metionina } \\
\text { DL-Methionine }\end{array}$ & 0,17 & 0,20 \\
\hline $\begin{array}{l}\text { L-lisina. } \mathrm{HCl} \\
\text { L-lysine } \mathrm{HCl}\end{array}$ & 0,11 & 0,19 \\
\hline $\begin{array}{l}\text { Suplemento vitamínico } \\
\text { Vitamin premix }\end{array}$ & 0,10 & 0,10 \\
\hline $\begin{array}{l}\text { Suplemento mineral } \\
\text { Mineral premix }\end{array}$ & 0,05 & 0,05 \\
\hline Cloreto de colina & 0,02 & 0,02 \\
\hline $\begin{array}{l}\text { Choline chloridre } \\
\text { Antioxidante }^{3}\end{array}$ & 0,01 & 0,01 \\
\hline $\begin{array}{l}\text { Antioxidant } \\
\text { Anticoccidiano } \\
\text { Coccidiostatic }\end{array}$ & 0,01 & 0,01 \\
\hline
\end{tabular}

Calculado $^{4}$

Calculated

\begin{tabular}{lc}
\hline $\begin{array}{l}\text { Proteína bruta (\%) } \\
\text { Crude protein }\end{array}$ & 16,00 \\
$\begin{array}{l}\text { Energia metabolizável (kcal/kg) } \\
\text { Metabolizable energy }\end{array}$ & 2780 \\
$\begin{array}{l}\text { Cálcio (\%) } \\
\text { Calcium }\end{array}$ & 3,42 \\
$\begin{array}{l}\text { Fósforo disponível (\%) } \\
\text { Available P }\end{array}$ & 0,34 \\
$\begin{array}{l}\text { Aminoácidos sulfurosos (\%) } \\
\text { AAS }\end{array}$ & 0,68 \\
Lisina $(\%)$ & 0,81 \\
Lysine
\end{tabular}

1 Composição/kg: Vit. A - 12.000.000 UI; Vit. $D_{3}$ - 3.600.000 UI; Vit. E - 3500 Ul; Vit. $B_{1}$ - 2500 mg; Vit. $B_{2}$ - 8000 mg; Vit. $B_{6}$ - 3000 mg; Ác. Pant. - $12.000 \mathrm{mg}$; Biotina - $200 \mathrm{mg}$; Vit. K - $3000 \mathrm{mg}$; Ác. fólico (Folic acid) - 3500 mg; Ác. nicotínico (Nicotinic acid) - 40.000 mg; Vit. $\mathrm{B}_{12}-20.000 \mathrm{mg}$; Selênio - $130 \mathrm{mg}$; Veículo q.s.p. - $1000 \mathrm{~g}$.

2 Composição/kg: Mn - 160 g; Fe - 100 g; Zn - 100 g; Cu - 20 g; Co - 2 g; I - 2 g; Excipiente q.s.p. - 1000 g.

3 Antioxidante (Antioxidant): BHT (Butil-Hidróxi-tolueno).

4 Composição calculada segundo ROSTAGNOetal. (1996) (Composition calculated according to ROSTAGNO et al., 1996).

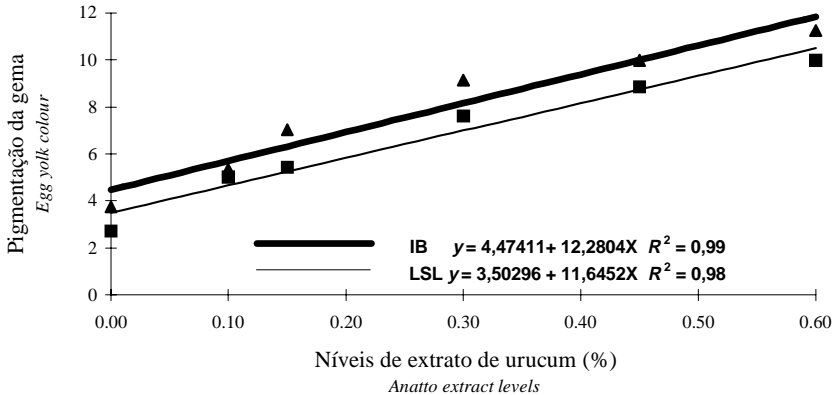

Figura 1 - Efeito de níveis crescentes de extrato de urucum na ração sobre a pigmentação da gema dos ovos de duas linhagens comerciais.

Figure 1 - Effect of increase levels of anatto extract in the diet on yolk egg colour of two commercial strains.

(1955), usando farinha de urucum em rações nas quais o milho foi substituído em $30 \%$ pelo adlai (Coix lacrima Jobi, Lin). A adição de $2 \%$ do produto produziu gemas de coloração laranja mais forte que a obtida com a adição de $1 \%$, sendo esta cor a preferida do consumidor brasileiro. SANCHEZ (1965) também recomendou o uso de $3 \%$ de farinha de urucum em rações em que o milho foi substituído em 30 e $50 \%$ por alimentos pobres em xantofilas.

As linhagens diferiram na capacidade de pigmentar a gema, sendo que as poedeiras semipesadas foram mais eficientes $(P>0,05)$. Este resultado pode estar relacionado a diferenças na taxa de digestão, absorção e deposição de pigmentos do urucum na gema.

Segundo KLASSING (1998), a deposição de pigmento em tecidos específicos é dependente da quantidade apropriada na dieta, da taxa de deposição no tecido em crescimento e da capacidade da ave em digerir, absorver e metabolizá-lo. A etapa limitante do aproveitamento de um pigmento é o ataque hidrolítico de esterases intestinais específicas, com baixa digestão, quando o pigmento está esterificado aos ácidos graxos de cadeia longa. Os carotenóides livres são absorvidos juntamente com os ácidos graxos dissolvidos nas micelas e transportados por lipoproteínas no sangue.

Como a pigmentação da gema é uma característica importante para valorização e aceitação do ovo pelos consumidores e fabricantes de massas, linhagens com esta característica devem resultar em melhor preço pago pelo ovo aos produtores.

As rações controle e as com $0 ; 0,10 ; 0,15 ; 0,30$; 0,45 ; e $0,60 \%$ apresentaram, respectivamente, custos 
Tabela 2 - Efeito de diferentes níveis de extrato oleoso de urucum (EU) sobre produção de ovos, peso médio dos ovos e pigmentação da gema dos ovos em poedeiras de ovos brancos (LSL) e ovos marrons (IB)

Table 2 - Effect of different levels of annato extract (AE) oil on egg production, average egg weight and egg yolk colour in white-egg (LSL) and brown-egg (IB) layers

\begin{tabular}{|c|c|c|c|c|c|c|}
\hline \multirow[t]{2}{*}{$\begin{array}{l}\text { Tratamento } \\
\text { Treatment }\end{array}$} & \multicolumn{2}{|c|}{$\begin{array}{l}\text { Produção de ovo }(\%) \\
\text { Egg production }\end{array}$} & \multicolumn{2}{|c|}{$\begin{array}{l}\text { Peso do ovo (g/dia) } \\
\text { Egg weight (g/day) }\end{array}$} & \multicolumn{2}{|c|}{$\begin{array}{c}\text { Pigmentação da gema } \\
\text { Egg yolk color }\end{array}$} \\
\hline & LSL & IB & LSL & $\mathrm{IB}$ & $\mathrm{LSL}^{1}$ & $\mathrm{IB}^{1}$ \\
\hline Controle (Control) & 77,8 & 80,1 & 63,6 & 65,6 & $5,10^{\mathrm{d}}$ & $5,83^{\mathrm{e}}$ \\
\hline \multicolumn{7}{|l|}{ EU $A E$} \\
\hline 0,00 & 68,0 & 76,1 & 62,9 & 65,9 & $2,73^{\mathrm{e}}$ & $3,75^{\mathrm{f}}$ \\
\hline 0,10 & 67,1 & 76,7 & 58,4 & 64,7 & $5,02^{d}$ & $5,35^{\mathrm{e}}$ \\
\hline 0,15 & 70,2 & 77,9 & 63,3 & 65,1 & $5,43^{d}$ & $7,03^{\mathrm{d}}$ \\
\hline 0,30 & 73,8 & 69,2 & 63,1 & 68,0 & $7,62^{\mathrm{c}}$ & $9,15^{\mathrm{c}}$ \\
\hline 0,45 & 64,6 & 71,1 & 63,8 & 65,6 & $8,87^{b}$ & $9,99^{\mathrm{b}}$ \\
\hline 0,60 & 75,7 & 75,2 & 62,8 & 65,3 & $9,98^{\mathrm{a}}$ & $11,24^{\mathrm{a}}$ \\
\hline Médias (Means) & $71,1^{\mathrm{A}}$ & $75,2^{\mathrm{A}}$ & $62,6^{\mathrm{B}}$ & $65,7^{\mathrm{A}}$ & $6,39^{\mathrm{B}}$ & $7,47^{\mathrm{A}}$ \\
\hline $\mathrm{CV} \%$ & \multicolumn{2}{|c|}{13,37} & \multicolumn{2}{|c|}{5,51} & \multicolumn{2}{|c|}{7,88} \\
\hline
\end{tabular}

1 Efeito linear $(\mathrm{P}<0,01)$.

Médias, na coluna, seguidas de letras iguais não diferem pelo teste Newman Keuls $(P>0,05)$.

Médias, na linha, seguidas de mesma letra maiúscula não diferem pelo teste $F(P>0,05)$.

1 Linear effect $(P<.01)$.

Means, within a column, within each variable, followed by the same letters do not differ by Newman Keuls test $(P>.05)$.

Means, within a row, within each variable, followed by the same letters do not differ by $F$ test $(P>05)$.

Tabela 3 - Efeito de diferentes níveis de extrato oleoso de urucum (EU) sobre consumo médio de ração, massa de ovos e conversão alimentar por dúzia de ovos em poedeiras de ovos brancos (LSL) e ovos marrons (IB)

Table 3 - Effect of different levels of annato extract (AE) oil on average feed intake, egg mass and feed:egg dozen in whiteegg (LSL) and brown-egg (IB) layers

\begin{tabular}{|c|c|c|c|c|c|}
\hline \multirow[t]{2}{*}{$\begin{array}{l}\text { Tratamento } \\
\text { Treatment }\end{array}$} & \multirow{2}{*}{$\begin{array}{l}\text { Consumo } \\
\text { Feed intake } \\
(\mathrm{g} / \mathrm{d})\end{array}$} & \multicolumn{2}{|c|}{$\begin{array}{c}\text { Massa de ovo (g/ave/d) } \\
\text { Egg mass }\end{array}$} & \multicolumn{2}{|c|}{$\begin{array}{l}\text { Conversão (g/dz) } \\
\text { Feed:dozen egg }\end{array}$} \\
\hline & & $\mathrm{PL}$ & PSP & $\mathrm{PL}$ & PSP \\
\hline Controle (Control) & 115,8 & 49,5 & 52,6 & 1,76 & 2,27 \\
\hline \multicolumn{6}{|l|}{$\mathrm{EU}(A E)$} \\
\hline 0,00 & 114,0 & 42,9 & 50,0 & 1,95 & 2,40 \\
\hline 0,10 & 113,6 & 38,8 & 49,6 & 1,92 & 2,50 \\
\hline 0,15 & 115,8 & 44,6 & 50,8 & 1,95 & 2,54 \\
\hline 0,30 & 114,6 & 46,6 & 47,0 & 2,07 & 2,60 \\
\hline 0,45 & 113,3 & 40,9 & 46,7 & 1,98 & 2,56 \\
\hline 0,60 & 114,0 & 47,5 & 49,0 & 1,84 & 2,39 \\
\hline Média (Mean) & 114,4 & $44,4^{\mathrm{B}}$ & $49,4^{\mathrm{A}}$ & $1,92^{\mathrm{B}}$ & $2,46^{\mathrm{A}}$ \\
\hline CV\% & 2,89 & \multicolumn{2}{|c|}{13,96} & \multicolumn{2}{|c|}{12,29} \\
\hline
\end{tabular}

AB Médias na linha, dentro de cada variável, seguidas de mesma letra não diferem pelo teste $F(P>0,05)$.

$A B$ Means, within a row, followed by the same letter do not differ by $F$ test $(P>.05)$. 
Rev. bras. zootec.

de $\mathrm{R} \$ 0,229 ; 0,217 ; 0,224 ; 0,228 ; 0,238 ; 0,248 ; \mathrm{e} 0,259 / \mathrm{kg}$. Como a ração representa $75 \%$ do custo total de produção, concluiu-se que a adição de 0,10 a $0,15 \%$ de EU à ração foi economicamente mais viável. $\mathrm{O}$ uso de níveis mais elevados nas rações de poedeiras depende do pagamento diferenciado do ovo pelo grau de pigmentação da gema.

A adição de níveis acima de $0,40 \%$ de extrato de urucum à ração contendo sorgo (Figura 1) produziu pigmentação da gema dos ovos semelhante à obtida com aves caipiras de 8,5-9,0 (SILVA ${ }^{1}$, dados nãopublicados) pontos de escore no leque da Roche. Este resultado sugere a possibilidade de produção do ovo tipo caipira em condições de criação comercial, resultando, aparentemente, em valorização e maior aceitação dos ovos por parte dos consumidores.

\section{Conclusões}

$\mathrm{A}$ adição de $0,1 \%$ do extrato de urucum às rações de poedeiras contendo $40 \%$ de sorgo resulta em pigmentação da gema dos ovos similar à obtida com rações contendo milho como fonte de energia. Poedeiras semipesadas produzem gemas com pigmentação superior às poedeiras leves.

\section{Referências Bibliográficas}

ARRAYA, H.H., MURILLO, M.R., VARGAS, E.G. et al. 1977. Composicion y empleo del achiote (Bixa orellana L.) en raciones para gallinas ponedoras, para la pigmentacion de la yema del huevo. Agronomia Costariquense, 1(2):143-150.

CAMPOS, J. 1955. Efeito do urucum na cor da gema de ovo. Revista Ceres, 9(53):349-353.

CARVALHO, P.R.N., HEIN, M. 1989. Urucum - uma fonte de corante natural. Colet. Ital, 19(1):25-33.
DAMASCENO, V. 1988. Guerra aos sintéticos ressuscita os naturais. Química e Derivados, (3):10-20.

FIALHO, E.T., BARBOSA, H.P. 1997. Alimentos alternativos para suínos. Lavras, MG: FAEPE. 228p.

KLASSING, K.C. 1998. Comparative avian nutrition. New York: CAB International. 350p.

LANCINI, J.B. 1994. Aditivos. In: FACTA. Fisiologia da digestão e absorção de aves. Campinas, SP: FACTA. p.99-126.

MASCARENHAS, J.M.O., STRINGHETA, P.C. 1998. Corantes naturais. Rev. Nac. Carne, (256):32-33.

NYACHOTI, C.M., ATKINSON, J.L., LEESON, S. 1997. Sorghum tannins: a review. World's Poult. Sci. J., 53:5-21.

PUPA, J.M.R. Rações para frangos de corte formuladas com valores de aminoácidos digestíveis verdadeiros, determinados com galos cecectomizados. Viçosa, MG: UFV, 1995. 63p. Dissertação (Mestrado em Zootecnia) - Universidade Federal de Viçosa, 1995.

ROSTAGNO, H.S., BARBARINO JR., P., BARBOZA, W.A. 1996. Exigências nutricionais das aves determinadas no Brasil. In: SIMPÓSIO INTERNACIONAL SOBRE EXIGÊNCIAS NUTRICIONAIS DE AVES E SUÍNOS. Viçosa. Anais... Viçosa: UFV, 1996. p.361-388.

SANCHEZ, R.M. 1965. El achiote. Agricultura Tropical, 21(4):224-227.

UNIVERSIDADE FEDERAL DE VIÇOSA - UFV. 1982. Central de Processamento de Dados - UFV/CPD. SAEG - Sistema de análises estatísticas e genéticas. Viçosa, MG. 52p. (Manual do usuário).

VILLELA, G.G. 1942. Sobre a suposta presença de caroteno nas sementes do urucum (Bixa orellana Linn.). Rev. Bras. Biologia, 2(2):159-164.

WILLIAMS, W.D. 1989. La pigmentación en las aves. Avicultura professional, 7:60-68.

${ }^{1}$ SILVA, J.H.V. Informação pessoal, 1999.

Recebido em: 05/10/99

Aceito em: 15/02/00 